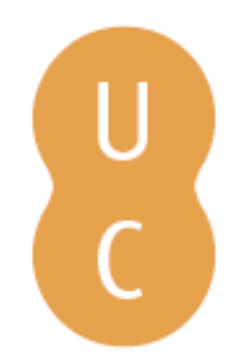

\title{
nommalina
}

\section{Avaliação municipal da vulnerabilidade a inundação por tsunami}
Autor(es):
Fonte, André; Barros, José Leandro; Tavares, Alexandre Oliveira; Santos, Ângela

Publicado por: Imprensa da Universidade de Coimbra

URL

persistente:

URI:http://hdl.handle.net/10316.2/38291

DOI:

DOI:http://dx.doi.org/10.14195/9789892610993_9

Accessed : $\quad$ 26-Apr-2023 13:04:48

A navegação consulta e descarregamento dos títulos inseridos nas Bibliotecas Digitais UC Digitalis, UC Pombalina e UC Impactum, pressupõem a aceitação plena e sem reservas dos Termos e Condições de Uso destas Bibliotecas Digitais, disponíveis em https://digitalis.uc.pt/pt-pt/termos.

Conforme exposto nos referidos Termos e Condições de Uso, o descarregamento de títulos de acesso restrito requer uma licença válida de autorização devendo o utilizador aceder ao(s) documento(s) a partir de um endereço de IP da instituição detentora da supramencionada licença.

Ao utilizador é apenas permitido o descarregamento para uso pessoal, pelo que o emprego do(s) título(s) descarregado(s) para outro fim, designadamente comercial, carece de autorização do respetivo autor ou editor da obra.

Na medida em que todas as obras da UC Digitalis se encontram protegidas pelo Código do Direito de Autor e Direitos Conexos e demais legislação aplicável, toda a cópia, parcial ou total, deste documento, nos casos em que é legalmente admitida, deverá conter ou fazer-se acompanhar por este aviso.

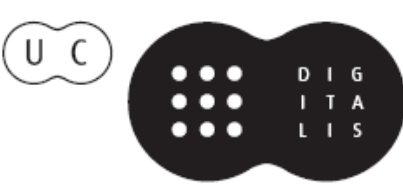




\section{TERRAMOTO DE \\ LISBOA DE 1755}

\section{O QUE APRENDEMOS \\ 260 ANOS DEPOIS?}

LUCIANO LOURENÇO

ÂNGELA SANTOS

(COORDS.)

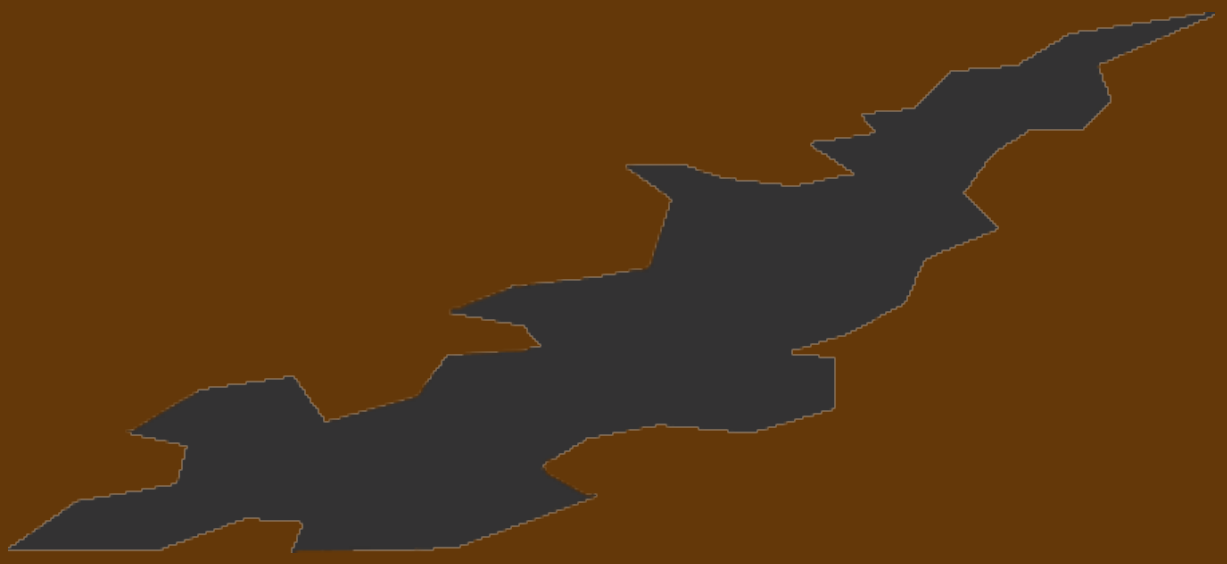

IMPRENSA DA UNIVERSIDADE

DE COIMBRA

COIMBRA

UNIVERSITY

PRESS 


\title{
AVALIAÇÃO MUNICIPAL DA VULNERABILIDADE A INUNDAÇÃO POR TSUNAMI
}

\author{
MUNICIPAL VULNERABILITY ASSESSMENT FOR \\ TSUNAMI INUNDATION
}

\begin{abstract}
André Fonte
Centro de Estudos Geográficos, IGOT, Universidade de Lisboa marioandre.uc@gmail.pt

José Leandro Barros

Centro de Estudos Geográficos, IGOT, Universidade de Lisboa joseleandrobarros@gmail.pt

Alexandre Oliveira Tavares

Centro de Estudos Sociais e Dep. de Ciências da Terra, Universidade de Coimbra atavares@ci.uc.pt Ângela Santos

Centro de Estudos Geográficos, IGOT, Universidade de Lisboa angela.santos@campus.ul.pt
\end{abstract}

Sumário: Diversas metodologias têm sido desenvolvidas com o objetivo de avaliar a vulnerabilidade face a tsunamis. O presente estudo apresenta a aplicaçáo de uma análise integrada multidimensional de avaliação da vulnerabilidade a tsunamis para os concelhos da Figueira da Foz, Vila do Bispo e Setúbal. É calculado o índice compósito de vulnerabilidade que agrega os índices de vulnerabilidade morfológica, estrutural, social e tributária, para a área potencialmente inundada utilizando como referência a modelação numérica da inundação do Tsunami de Lisboa de 1755.

Palavras-chave: Tsunami, vulnerabilidade, metodologia multidimensional, índice compósito de vulnerabilidade, Portugal. 


\begin{abstract}
Several methodologies have been developed with the aim of assessing the vulnerability to tsunamis. This paper presents the application of a multidimensional integrated analysis for the vulnerability assessment to tsunamis for the municipality of Figueira da Foz, Vila do Bispo and Setúbal. The composite vulnerability index, that aggregates morphological, structural, social and tax component vulnerability indices, is calculated to potentially inundated areas using as reference the inundation numerical modeling of the 1755 Lisbon Tsunami.
\end{abstract}

Keywords: Tsunami, vulnerability, multidimensional approach, composite vulnerability index, Portugal.

\title{
Introduçáo
}

Os registos históricos permitem identificar um total de 17 tsunamis ocorridos ao longo da costa portuguesa desde 60 a.C. atéista e Miranda, 2009) e o intervalo de tempo de 45 anos que o separa da atualidade faz com que várias geraçóes não tenham convivido com a manifestação de eventos deste tipo. Esta ausência faz com que haja um falso sentimento de segurança, o que condiciona a perceção da populaçáo em relação ao risco de tsunami. Em Portugal os valores relacionados com a perceçáo face a riscos naturais e tecnológicos são genericamente baixos, sendo esta tendência mais clara nas zonas mais próximas dos locais de residência (Tavares et al., 2011). O mesmo estudo conclui que quanto maior é a proximidade à zona de residência menor é a intensidade percebida dos processos perigosos, influenciada pela noçáo de segurança e controlo dos acontecimentos. O estudo levado a cabo por Mendes e Freiria (2012) do observatório do Risco OSIRIS demonstra que num conjunto de 28 riscos, tsunami surge em último lugar numa lista que identifica a importância dos riscos percecionados pelos portugueses. Por outro lado, o estudo realça ainda que $95 \%$ dos inquiridos náo adotam qualquer medida de prevençáo face a um tsunami, concluindo que a perceçáo do 
risco de tsunami em Portugal é muito baixa, mesmo para as populaçóes que habitam na zona costeira ou em estuários.

A vulnerabilidade, independentemente da sua natureza, apresenta uma variaçáo e heterogeneidade ao longo do território sendo influenciada pelos múltiplos fatores e características intrínsecas ao mesmo. Estando o risco intimamente relacionado com a vulnerabilidade é cada vez mais necessário a criação e adoçáo de metodologias multidimensionais que agreguem em seu torno as múltiplas realidades inerentes ao perigo e à vulnerabilidade. No que respeita ao risco de tsunami, os recentes acontecimentos verificados em 2004 no Oceano Indico e em 2011 no Japão despoletaram um conjunto de metodologias de avaliaçáo do risco de tsunami. No entanto, muitas dessas metodologias focam-se apenas na componente estrutural da vulnerabilidade, realizando desta forma uma análise e avaliação incompleta (Dall'Osso et al. 2010). O presente estudo é inovador no sentido em que dá a conhecer uma análise integrada da vulnerabilidade, pelo que se distingue das demais metodologias pelo facto de ser uma abordagem multidimensional, abordando e introduzindo novas componentes na avaliaçáo da vulnerabilidade face a um tsunami.

Assim, os principais objetivos do presente estudo são: a representação cartográfica da área potencialmente inundável por um tsunami nos concelhos da Figueira da Foz, Vila do Bispo e de Setúbal; o cálculo do índice de vulnerabilidade morfológica $(\mathrm{VM})$ para a área potencialmente inundada; o cálculo do índice de vulnerabilidade estrutural (VE) para os edifícios potencialmente afetados; o cálculo do índice de vulnerabilidade social (VS) e tributária (VT). Por fim todos os índices são combinados para se obter o cálculo do índice compósito de vulnerabilidade (ICV) para as freguesias dos concelhos da Figueira da Foz, Vila do Bispo e Setúbal.

\section{Caracterização}

Este estudo remete-nos para três áreas costeiras portuguesas (Figueira da Foz, Vila do Bispo e Setúbal - fig.1a), com base em relatos históricos e nas características territoriais do Tsunami de Lisboa de 1755. 
A escolha da Figueira da Foz (fig. 1b) justifica-se por ser um centro urbano com forte presença antrópica e de infra-estruturas relevantes na zona costeira, pela grande flutuação diária e sazonal de população e pela existência de relatos históricos que mostram um run-up extremo de $36 \mathrm{~m}$ (Santos et al., 2012).

A opção de Setúbal (fig. 1c) justifica-se pela existência de relatos históricos, pela elevada densidade populacional e por ser dotado de uma importante zona industrial no panorama nacional e internacional (Santos e Koshimura, 2013). A escolha de Vila do Bispo (fig. 1d) deve-se à existência de relatos históricos associados ao tsunami de de Lisboa de 1755 (Santos, 2008; Santos et al., 2011) e com o facto de um tsunami com uma origem semelhante ao verificado em 1755 demorar menos de 20 minutos a atingir o concelho (Santos et al., 2009). Por último, a existência de aglomerados populacionais junto à costa (Sagres, Burgau e Salema) e a sua considerável flutuação populacional sazonal justificam o seu estudo.

Importa referir que os limites das freguesias utilizados no estudo dizem respeito aos limites anteriores à reorganização autárquica efetuada em 2013.
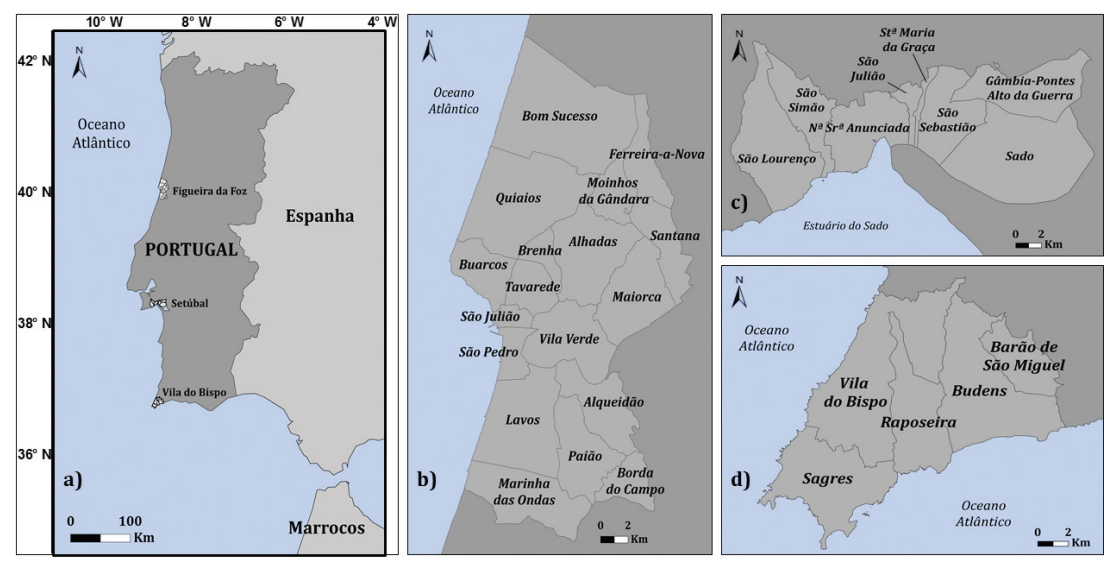

Fig. 1 - a) Enquadramento da área de estudo; b) Município da Figueira da Foz; c) Município de Setúbal; d) Município de Vila do Bispo.

Fig. 1 - a) Framework of the study area; b) Municipality of Figueira da Foz; c) Municipality of Setúbal; d) Municipality of Vila do Bispo. 


\section{Figueira da Foz}

\section{Caracterização morfológica}

O concelho da Figueira da Foz está localizado no bordo oeste Meso-Cenozóico, onde a base é composta em grande parte de material sedimentar, calcários (Dogger) (Rocha et al., 1981). A altimetria da área de estudo varia entre 0 e $257 \mathrm{~m}$ na Serra da Boa Viagem, que está localizado no centro do município e se destaca em termos de relevo. A norte e a sul do alinhamento formado pela Serra da Boa Viagem e da Serra das Alhadas as planícies são predominantes, com elevações inferiores a $100 \mathrm{~m}$, incluindo a planície de inundação do Mondego e a planície costeira. Os declives predominantes na área de estudo têm valores $<5 \%$, com os maiores valores localizados na encosta norte da Serra da Boa Viagem.

A orla costeira é caracterizado em termos gerais como sendo uma área plana de baixa altitude, com exceção da Serra da Boa Viagem. Ao norte deste sistema montanhoso existe uma extensa planície costeira com formações de dunas bem desenvolvidas (Almeida, 1995). O sul também é dominado por planícies costeiras onde começa o estuário e dunas de areias do Mondego que formam dunas frontais. A área do Cabo do Mondego é dominada por falésias na base na qual se desenvolve uma plataforma rochosa de abrasão (Cunha et al., 1997). O litoral adjacente à cidade da Figueira da Foz é caracterizado pela existência de uma praia com cerca de $500 \mathrm{~m}$ de comprimento, resultado da retenção de sedimentos pelo molhe norte do porto da Figueira da Foz. $\mathrm{Na}$ foz do rio Mondego estão localizados dois esporóes e outra infraestrutura em que ambos tentam proteger a zona do porto e influenciar a dinâmica litoral.

\section{Caracterização socioeconómica}

Em termos administrativos, o concelho da Figueira da Foz pertence à denominada região Centro (NUT II), sub-região do Baixo Mondego (NUT III), abrangendo uma área de $379 \mathrm{~km}^{2}$. É delimitado a norte pelo município 
de Cantanhede, a este por Montemor-o-Velho e Soure, a sul por Pombal e a oeste pelo Oceano Atlântico.

De acordo com os Censos de 2011 (INE, 2011), o município regista uma população de 62125 habitantes, distribuídos de forma desigual entre as 18 freguesias, com uma densidade populacional de $163,3 \mathrm{hab} . / \mathrm{Km}^{2}$. A Figueira da Foz destaca-se como sendo uma cidade de média dimensão no panorama nacional, com um total de 28338 habitantes, onde a sazonalidade da ocupação humana é distinta. De acordo com os Censos de 2011 (INE, 2011), o município apresenta um total de 24893 edifícios e 43300 alojamentos, com uma concentraçâo maior na área costeira. Em termos de setores de atividade, há uma clara predominância do setor terciário $(64,9 \%)$, seguido do setor secundário $(31,6 \%)$ e primário $(3,5 \%)$. Também digno de registo é a existência do porto da Figueira da Foz como um centro dinâmico da economia local e regional.

\section{Setúbal}

\section{Caracterização morfológica}

Em termos geomorfológicos, consideram-se na região de Setúbal três grandes unidades: área montanhosa, área planáltica e baixas aluvionares (Coelho, 1980).

A área montanhosa compreende um conjunto de relevos alinhados com orientação geral SW-NE, dispostos em arcos sucessivos, onde se destacam a "cuesta" oligomiocénica de Azeitão-Palmela (Serra de S. Francisco - 257m e Serra do Louro - 224m), os relevos monoclinais formados pelos terrenos da Série Continental Neojurássica e Cretácica (Serra de Gaiteiros - 238m, Vales das ribeiras de Alcube e de Corava, Serra de Comenda - 190m e Serra do Viso - 163m) e o monte anticlinal de S. Luís (392m) e o flanco Norte do monte anticlinal do Formosinho.

A área planáltica constitui a área aplanada que envolve a norte e a leste a área montanhosa. Por outro lado, as baixas aluvionares, caracterizam-se por 
constituírem zonas planas de cotas baixas com declives inferiores a 2\%, passando nas zonas de montante a declives entre 2 e 5\% (LNEG, 1994).

Nestas baixas aluvionares considera-se o estuário do Sado formado em grande parte por planícies aluviais com uma altitude média muito baixa. Podem encontrar-se ainda outros tipos de formaçáo como dunas, praias (fluviais e marítimas) e alguns afloramentos plistocénicos e miocénicos. Em ambas as margens existem sapais que são entrecortados por esteiros e canais (ICNF, 2015).

\section{Caracterização socioeconómica}

Em termos administrativos, o concelho de Setúbal tem função de capital de distrito e pertence à região de Lisboa (NUT II), sub-região da Península de Setúbal (NUT III), sendo delimitado a oeste pelo município de Sesimbra, a noroeste pelo município do Barreiro, a norte e nordeste pelo município de Palmela, e a sul e sudoeste pelo estuário do Sado. Abrange uma área de 172 $\mathrm{Km}^{2}$. O município é dividido em 8 freguesias, que apresentam, no seu conjunto, características urbano-rurais.

Em termos populacionais o município de Setúbal possuía, em 2011, um total de população residente de 121185 habitantes, um aumento de cerca de 6\% face aos números registados em 2001 (113 934) (INE, 2011). Até aos anos 1960, a população residente aumentou sobretudo com base no crescimento natural, acompanhando o desenvolvimento das indústrias conserveiras e do setor terciário, ligado ao comércio e transportes (Faria, 1981), tendo este aumento populacional se mantido nas décadas seguintes, associado ao forte desenvolvimento industrial. A melhoria das acessibilidades, a proximidade com Lisboa, e sobretudo a implantação de indústria e necessidade de mão-de-obra levou à fixação de população oriunda do interior do pais e também de ex-colónias portuguesas, desencadeando um forte movimento migratório (Faria, 1981), assumindo um posicionamento estratégico de polarizaçáo regional e integrando-se nas mais importantes rotas marítimas internacionais. 
De acordo com os Censos de 2011 (INE, 2011), o município relata um total de 24242 edifícios e 62829 alojamentos. Em termos de setores de atividade, há uma clara predominância do setor terciário $(73,5 \%)$, seguido do setor secundário $(24,9 \%)$ e primário $(1,6 \%)$.

\section{Vila do Bispo}

\section{Caracterizaçáo morfológica}

O concelho de Vila do Bispo pertence, em termos morfo-estruturais, à chamada zona sul e é representado por unidades litológicas do Meso-Cenozóico (Rocha et al., 1979). Há vários registos de sedimentos do tsunami de 1755 na área, especificamente na Boca do Rio (Dawson et al., 1995). A altimetria varia entre os 0 e $150 \mathrm{~m}$ predominando as encostas com declives $<5 \%$. Os valores mais elevados estáo localizados em áreas ao longo das falésias costeiras ou em áreas com declives acentuados, que são entalhados por vales fluviais costeiros.

O litoral do município de Vila do Bispo está enquadrado na área protegida do Parque Natural do Sudoeste Alentejano e da "Costa Vicentina". A zona costeira tem uma grande diversidade morfológica, dominada pelas áreas rochosas de penhascos íngremes com dezenas de metros de altura, com o desenvolvimento disperso de áreas arenosas que são frequentemente associadas a áreas na boca de pequenos rios e ribeiras.

Há também processos erosivos e episódios de regressão costeira, principalmente em áreas rochosas, onde há muitas vezes a ocupaçáo humana na base ou no topo de um penhasco (e.g. praia do Beliche e Zavial - fig. 5a).

\section{Caracterizaçáo socioeconómica}

Em termos administrativos, o concelho de Vila do Bispo pertence ao Algarve (NUT II), sub-regiāo do Algarve (NUT III), sendo delimitado a norte pelo 
município de Aljezur, a este por Lagos, e a sul e a oeste pelo Oceano Atlântico. Localizado na zona mais a sudoeste do território continental, o concelho insere-se na regiâo denominada de Barlavento Algarvio e abrange uma área de $179 \mathrm{~km}^{2}$.

De acordo com os Censos de 2011 (INE, 2011), o concelho apresenta uma população de 5381 habitantes, abrangendo um total de 5 freguesias e apresentando uma baixa densidade populacional $\left(29,2 \mathrm{hab} / \mathrm{Km}^{2}\right)$. O concelho tem um total de 5184 edifícios e 5979 alojamentos (INE, 2011). No que respeita a aglomerados populacionais destaca-se Vila do Bispo que é a sede de concelho e se localiza na zona central do mesmo. Junto à costa destacam-se Sagres, Salema e Burgau como locais de maior concentraçáo populacional. Em termos de setores de atividade, existe um claro predomínio do setor terciário $(81,2 \%)$, seguido do setor secundário $(11,1 \%)$ e primário $(7,7 \%)$.

\section{Metodologia}

Várias metodologias abordam a vulnerabilidade face a um tsunami, nomeadamente com enfoque na sua dimensão estrutural (Papathoma et al., 2003; Papathoma e Dominey-Howes, 2003; Dominey-Howes e Papathoma, 2007; Dall'Osso et al., 2009; Dall'Osso, 2010; Ismail et al., 2012).

O presente estudo é inovador pois apresenta uma metodologia multidimensional com base nas componentes de vulnerabilidade morfológica, estrutural, social e tributária face a um tsunami, tendo como base os trabalhos de Pendleton et al., 2010 e Ismail et al., 2012 (componente morfológica), Dall'Osso et al., 2009 (componente estrutural), Cutter et al., 2003, Schmidtlein et al., 2008, Mendes, 2009 e Chen et al., 2013 (componente social e económica) e os coeficientes de afetação que servem de base para o cálculo Imposto Municipal sobre Imóveis (IMI) disponíveis no site: http://www.e-financas.gov.pt/SIGIMI/default.jsp.

Para tal foram recolhidos e analisados um total de 18 parâmetros para o cálculo da componente morfológica e estrutural, 47 variáveis socioeconómicas para a componente social e 4 coeficientes de afetaçáo para o cálculo da componente tributária. 
Esta abordagem metodológica tem como finalidade o cálculo do Índice Compósito de Vulnerabilidade (ICV), que combina as diferentes componentes territoriais. Todas as quatro componentes territoriais e o valor compósito final variam de muito baixo a muito alto, de acordo com o desvio padrão e com as seguintes categorias: "muito baixo", <1SD; "baixo", [-1, -0.5 [SD; "moderado", [-0.5, 0.5 [SD; "alto", [0.5, 1 [SD; "muito alto", $\geq 1$ SD (Cutter et al., 2003).

A definição das áreas potencialmente afetadas foi realizada com recurso à modelação numérica de inundação por tsunami, tendo como referência o tsunami de 1 de Novembro de 1755 (Santos, 2008).

\section{Vulnerabilidade Morfológica}

O processo de análise referente à componente morfológica considera um total de cinco parâmetros: morfologia da área inundada $\left(\mathrm{p}_{1}\right)$, consolidação dos materiais geológicos $\left(\mathrm{p}_{2}\right)$, declive médio $\left(\mathrm{p}_{3}\right)$, distância à linha de costa $\left(\mathrm{p}_{4}\right)$ e uso e ocupação do solo ( $\left.\mathrm{p}_{5}\right)$. A análise e levantamento dos diferentes atributos pertencente a cada parâmetro, foi realizada com recurso a uma matriz que serviu de base para a realização de trabalho de campo, complementado com análise de imagens de satélite e utilizaçáo de tecnologia SIG. A matriz apresenta um conjunto de atributos intrínsecos a cada parâmetro e atribui a cada um, valores que variam entre $-1 \mathrm{e}+1$, sendo que os valores positivos representam um aumento da vulnerabilidade e os valores negativos um decréscimo da mesma.

No entanto nem todos os parâmetros assumem a mesma influência na vulnerabilidade morfológica. Como tal foi necessário atribuir diferentes ponderaçôes, tendo-se recorrido para o efeito ao software de análise multicritério M-Macbeth ${ }^{\bullet}$ (Bana e Costa et al., 2004) que através da comparaçấo direta entre os diferentes parâmetros permitiu atribuição de ponderaçóes consoante a importância de cada um.

O peso atribuído a cada parâmetro pode variar entre o 1 (valor mínimo) e os 100 (valor máximo). Após a ponderação de cada um dos parâmetros e da atribuição de valores a cada um dos seus atributos é calculada a VM com recurso à seguinte fórmula (Dall'Osso et al., 2009): 


$$
\boldsymbol{V} \boldsymbol{M}=\left(100 \mathrm{p}_{1}+76 \mathrm{p}_{2}+52 \mathrm{p}_{3}+38 \mathrm{p}_{4}+29 \mathrm{p}_{5}\right)
$$

Onde "p p" representa o valor atribuído a cada um dos parâmetros. Após o cálculo da VM é utilizado o seguinte algoritmo com o objetivo de reescalonar para o intervalo entre 0 e 1 .

$$
y=0.5\left(\frac{x}{a}+1\right)^{\log 2 / \log \left(\frac{b}{a}+1\right)}
$$

Onde "x" representa o valor direto da vulnerabilidade, "y" é o valor da vulnerabilidade reescalonada, "a" é o valor máximo da vulnerabilidade da amostra e "b" o valor mínimo.

\section{Vulnerabilidade Estrutural}

No que diz respeito à componente estrutural foram analisados os edifícios potencialmente afetados pelo modelo numérico de inundaçáo por tsunami (Santos, 2008). Foram considerados um total de 13 parâmetros que caracterizam os edifícios na sua vertente estrutural, ocupacional e funcional: número de pisos $\left(\mathrm{q}_{1}\right)$, material de construção $\left(\mathrm{q}_{2}\right)$, estado de conservação $\left(\mathrm{q}_{3}\right)$, tipo de fundação $\left(\mathrm{q}_{4}\right)$, hidrodinâmica do $\mathrm{R} / \mathrm{C}\left(\mathrm{q}_{5}\right)$, forma do edificado em planta $\left(\mathrm{q}_{6}\right)$ e altura emersa do edifício em relação à onda $\left(\mathrm{q}_{7}\right)$. Além destes foram introduzidos novos parâmetros relacionados com a ocupação, funcionalidade e estrutura dos edifícios (Barros et al., 2015 e Tavares et al., 2015) que não são contemplados nas metodologias precedentes, nomeadamente as apresentadas por Dall'Osso et al. (2009) e Ismail et al., (2012), o que veio complementar a análise dos edifícios através da sua distinção funcional, sazonal e ocupacional, bem como complementar a análise estrutural do mesmo, nomeadamente o ano de construção $\left(\mathrm{q}_{8}\right)$, existência de pisos subterrâneos $\left(\mathrm{q}_{9}\right)$, forma de ocupação $\left(\mathrm{q}_{10}\right)$, número de unidades de utilização $\left(\mathrm{q}_{11}\right)$, número médio diários de pessoas presentes ou visitantes por unidade de utilização $\left(\mathrm{q}_{12}\right)$ e flutuação da ocupação $\left(\mathrm{q}_{13}\right)$. A aquisição 
dos dados baseou-se na realizaçáo de trabalho de campo que permitiu não só a identificação dos edifícios potencialmente afetados como também a recolha das diversas características intrínsecas ao edifício e áreas envolventes.

Tal como referido anteriormente, foi elaborada uma matriz que agrega todos os parâmetros que compóem a componente estrutural da vulnerabilidade (VE). A matriz apresenta um conjunto de atributos intrínsecos a cada parâmetro e atribui a cada um, valores que variam entre -1 e +1 .

Tal como referenciado anteriormente, os 13 parâmetros pertencentes à componente estrutural contribuem de forma distinta para a vulnerabilidade, tendo sido necessário atribuição de ponderaçôes através do software de análise multicritério M-Macbeth (Bana e Costa et al., 2004).

Após a ponderação de cada um dos parâmetros e da atribuição de valores a cada um dos seus atributos é calculada a VE com recurso à seguinte fórmula (Dall'Osso et al., 2009):

$$
\begin{aligned}
V E & =\left(100 \mathrm{q}_{1}+97 \mathrm{q}_{2}+95 \mathrm{q}_{3}+92 \mathrm{q}_{4}+75 \mathrm{q}_{5}+72 \mathrm{q}_{6}+53 \mathrm{q}_{7}+50 \mathrm{q}_{8}+47 \mathrm{q}_{9}+\right. \\
37 \mathrm{q}_{10} & \left.+34 \mathrm{q}_{11}+32 \mathrm{q}_{12}+29 \mathrm{q}_{13}\right)
\end{aligned}
$$

Onde " $\mathrm{q}_{\mathrm{n}}$ " representa o valor atribuído a cada parâmetro.

\section{Vulnerabilidade Social}

Para o cálculo da Vulnerabilidade Social (VS) foram recolhidas e analisadas, com desagregação ao nível do concelho e da freguesia, um conjunto de 172 variáveis, de cariz social, económico, demográfico e relacionadas com o edificado da área de estudo (INE, 2013; PORDATA, 2013; Carta Social, 2013).

A vulnerabilidade social foi calculada com recurso à análise fatorial com recurso ao software SPSS $^{\bullet}$ que identificou um total de 47 variáveis: agricultura (3), alojamento e edifícios (19), economia (6), população (13), serviços (3) e apoio social (3) e um conjunto de 12 componentes, sendo 
que para este conjunto de dados foi atingido um $\mathrm{KMO}=0,717$, comunalidades superiores a 0,6 e uma taxa de variância de 78\%. Estes parâmetros atestam a elevada robustez das variáveis selecionadas para o cálculo da vulnerabilidade social. A matriz de componentes resultantes da análise fatorial permitiu selecionar um conjunto final de 6 componentes principais (Cutter et al., 2003; Schmidtlein et al., 2008; Mendes et al., 2011) que representam $61,7 \%$ da variância total. As restantes 6 componentes não foram consideradas uma vez que contribuíam com valores residuais para o total da variância.

O índice de vulnerabilidade social (VS) resultante foi produzido pela soma de todos os 12 fatores usando o mesmo peso, de acordo com Cutter et al. (2003) e Chen et al. (2013).

\section{Vulnerabilidade Tributária}

A combinação dos coeficientes de afetação (habitação, comércio, serviços e industria) que servem de base ao cálculo do Imposto Municipal sobre Imóveis (IMI) permitiu calcular a Vulnerabilidade Tributária (VT).

A inclusão destes dados na avaliação da vulnerabilidade face a um tsunami permite complementar todo o processo de análise, através do conhecimento da variação ao longo do território dos diferentes coeficientes de afetação para as diferentes atividades, permitindo classificar e diferenciar territórios, consoante as atividades implantadas, bem como, melhorar a identificação dos diferentes elementos expostos.

Para o cálculo da VT recorreu-se à seguinte fórmula:

$$
V T=\mathrm{a} \times \mathrm{b} \times \mathrm{c} \times \mathrm{d}
$$

Onde "a" é o valor do coeficiente de afetação referente à habitação, "b" ao comércio, "c" aos serviços e "d" o valor do coeficiente de afetação referente à indústria. 


\section{Índice Compósito de Vulnerabilidade}

Após o cálculo da VM, VE, VS e VT procede-se ao cálculo do ICV que agrega as quatro componentes (fig. 2) através da seguinte expressão:

$$
I C V=V M+V E+V S+V T
$$

O ICV varia entre 0 (vulnerabilidade mínima) e 4 (vulnerabilidade máxima), sendo as classes de vulnerabilidade definidas de acordo com o desvio padrão e as seguintes categorias: muito baixo: <-1SD; baixo: $[-1,-0.5[\mathrm{SD}$; moderado: $[-0.5,+0.5[\mathrm{SD}$; elevado: [0.5, 1 [SD; muito elevado: $\geq 1 \mathrm{SD}$ (Cutter et al., 2003).

\section{Dados e Resultados}

\section{Avaliação da Vulnerabilidade Morfológica}

O cálculo da VM permite concluir que a mesma é fortemente condicionada e influenciada pelo parâmetro "distância à linha de costa", assistindo-se a uma diminuição da vulnerabilidade com o aumento da distância (fig. 3). Este facto é visível no município da Figueira da Foz, nomeadamente na zona do Cabedelo (fig. 3c) e no Burgau, em Vila do Bispo (fig. 5d). Na Figueira da Foz a vulnerabilidade morfológica é ainda decisivamente influenciada quer pela "morfologia da área inundada", como também pelo fator "declive". Este facto verifica-se por exemplo na zona estuarina onde a vulnerabilidade é elevada devido à existência de zonas planas e de canais estreitos

Em Setúbal a VM é igualmente influenciada e condicionada pelo parâmetro "distância à linha de costa e pela "morfologia da área inundada". Neste último parâmetro, na zona oeste, a vulnerabilidade é baixa devido à existência de arribas e declives elevados, enquanto que na zona este o predomínio de zonas 


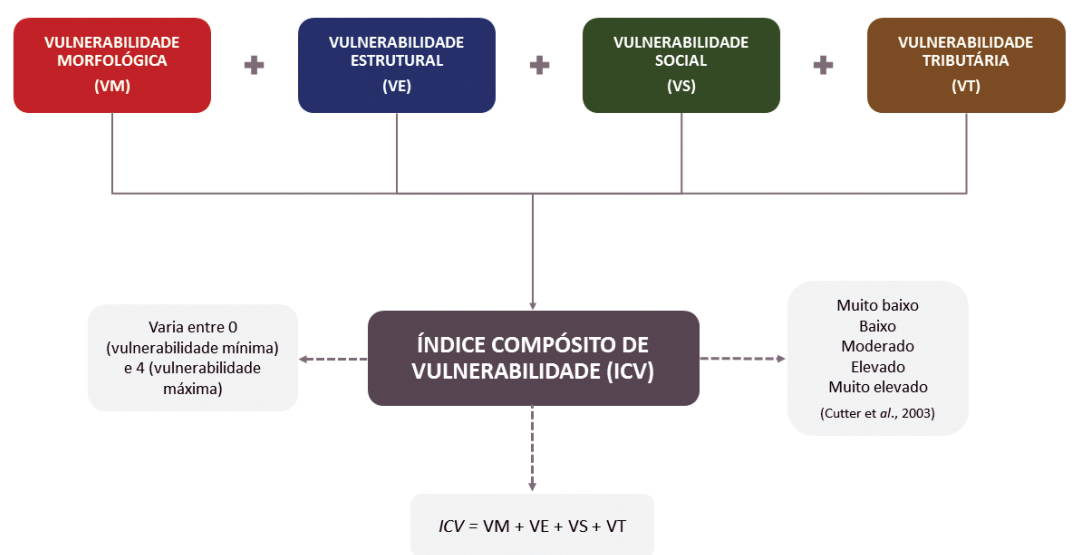

Fig. 2 - Índice Compósito de Vulnerabilidade.

Fig. 2 - Composite Vulnerability Index.
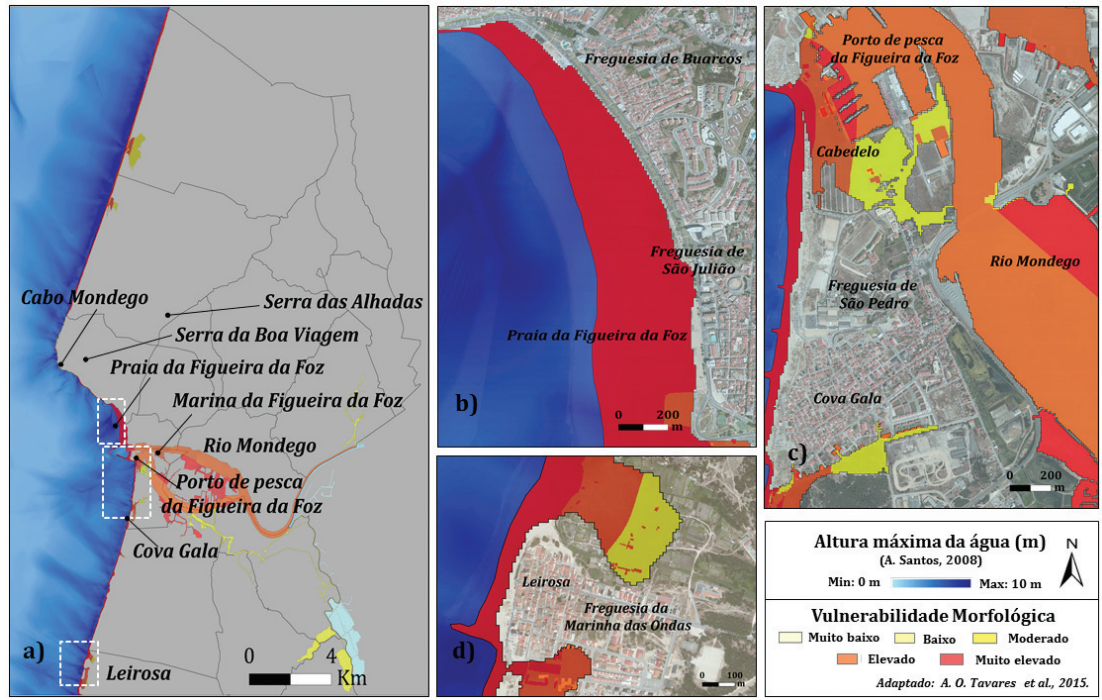

Fig. 3 - a) Avaliação da Vulnerabilidade Morfológica no município da Figueira da Foz; b) Detalhes nas freguesias de Buarcos e São Julião; c) Detalhes na freguesia de São Pedro (Cabedelo e Cova-Gala); d) Detalhes na freguesia da Marinha das Ondas (Leirosa).

Fig. 3 - a) Morphological vulnerability assessment in Figueira da Foz municipality; b) Details in Buarcos and São Julião parishes; c) Details in São Pedro parish (Cabedelo and Cova Gala); d) Details in Marinha das Ondas parish (Leirosa). 
planas e declives baixos, nomeadamente nas salinas e na Mitrena, resulta em vulnerabilidade elevada (fig. 4).

Em Vila do Bispo verifica-se também que a diferenciação da VM resulta em larga medida do parâmetro "distância à linha de costa", no entanto nesta área a morfologia (presença de arribas e declives elevados) e a ocupação antrópica valorizam os parâmetros "morfologia da área inundada", "declive" e "uso e ocupação do solo" e consequentemente o incremento da vulnerabilidade das áreas analisadas (fig. 5).

Em todos os municípios a vulnerabilidade morfológica varia entre muito baixa e muito elevada.

\section{Avaliação da vulnerabilidade estrutural}

Em termos de VE, o modelo numérico de inundação por tsunami com características idênticas ao de 1755, permitiu identificar um total de 1639 edifícios potencialmente afetados nos municípios em análise.

No que concerne à Figueira da Foz foram identificados 144 edifícios (fig. 6), com destaque para as áreas do Cabedelo e do porto (fig. 6c), Cova-Gala (fig. 6c) e Leirosa (fig. 6d). A vulnerabilidade estrutural do município varia entre muito baixa a muito elevada, sendo que 30\% (43 edifícios) apresentam uma vulnerabilidade elevada, 28\% (40 edifícios) vulnerabilidade muito baixa, 21\% (30 edifícios) moderada, 15\% (21 edifícios) muito elevada e por último 6\% (10 edifícios) apresentam uma vulnerabilidade estrutural baixa. A análise permite concluir que a grande maioria dos edifícios dos edifícios potencialmente afetados (92\%) estão localizados na margem esquerda do rio Mondego (Cabedelo, o porto, Cova Gala e Leirosa).

Relativamente a Setúbal (fig. 7) foram identificados um total de 1395 edifícios, onde a VE varia entre muito baixa a muito elevada. Em termos de vulnerabilidade dos edifícios, 454 apresentam uma vulnerabilidade moderada, 362 muito elevada, 302 elevada, 161 muito baixa e 116 apresentam uma vulnerabilidade baixa. Em termos de áreas destacam-se a área urbana da cidade de Setúbal (fig. 7c) e a zona industrial da Mitrena (fig. 7d). 


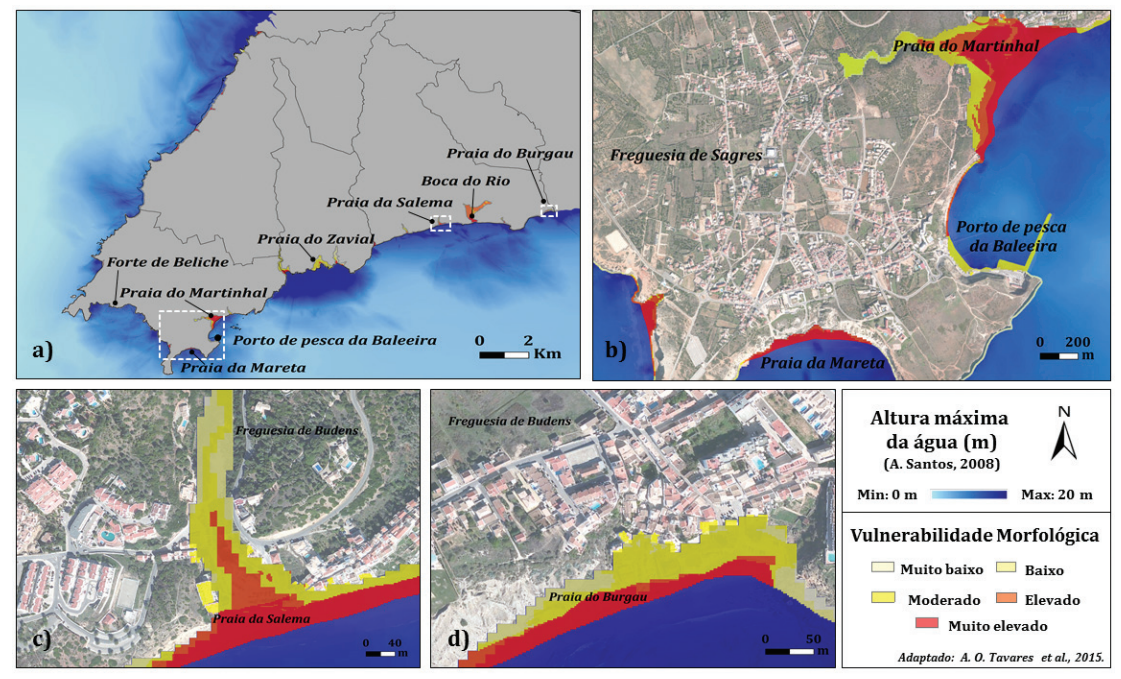

Fig. 4 - a) Avaliação da Vulnerabilidade Morfológica no município de Setúbal; b) Detalhes no Outão; c) Detalhes na área urbana de Setúbal; d) Detalhes na Mitrena. Fig. 4 - a) Morphological vulnerability assessment in Setúbal municipality; b) Details in Outäo; c) Details in urban area of Setúbal; d) Details in Mitrena.

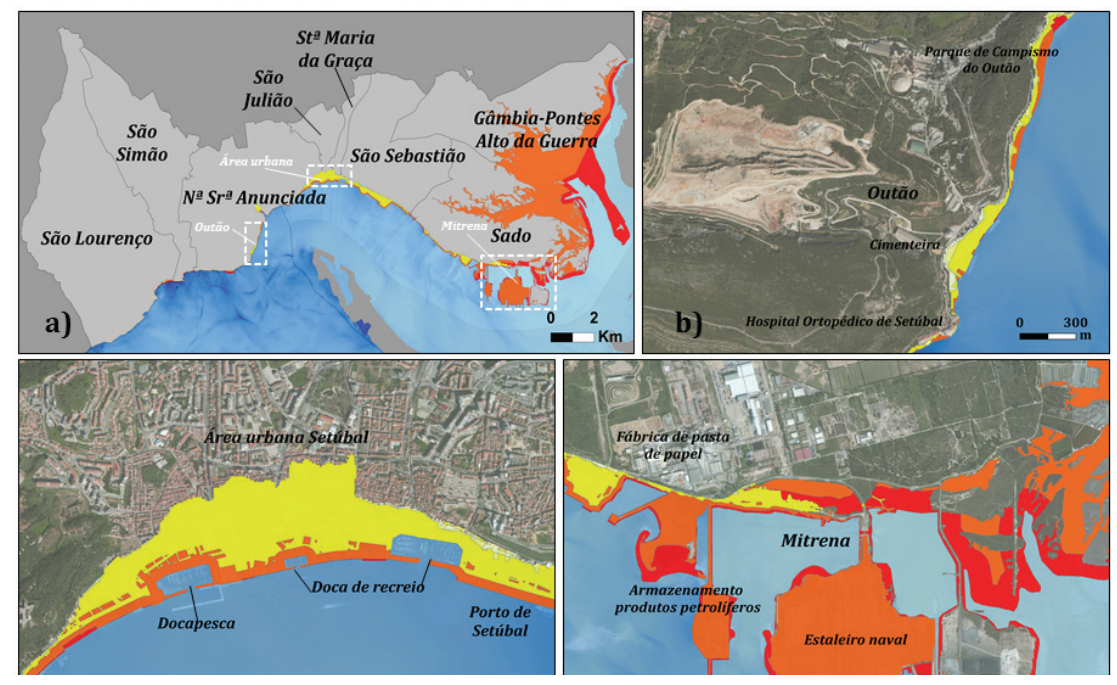

Fig. 5 - a) Avaliaçấo da Vulnerabilidade Morfológica no município de Vila do Bispo; b) Detalhes na freguesia de Sagres; c) Detalhes na freguesia de Budens (Salema); d) Detalhes na freguesia de Budens (Burgau).

Fig. 5 - a) Morphological vulnerability assessment in Vila do Bispo municipality: b) Details in Sagres parish; c) Details in Budens parish (Salema); d) Details in Budens parish (Burgau). 
No que respeita a Vila do Bispo (fig. 8) foram identificados um total de 100 edifícios, onde a VE varia entre muito baixa a muito elevada. Em termos de vulnerabilidade dos edifícios, 39 apresentam uma vulnerabilidade moderada, 18 muito baixa, 17 elevada, 15 muito elevada e 11 apresentam uma vulnerabilidade baixa. Em termos de áreas destacam-se a praia da Salema (fig. 8c), Burgau (fig. 8d) e Sagres, nomeadamente na área do porto de pesca da Baleeira (fig. 8b).

\section{Avaliação da vulnerabilidade social}

No município da Figueira da Foz (fig. 9a), composto por 18 freguesias, a VS varia entre baixa e muito elevada. As freguesias de São Pedro e Vila Verde são as que apresentam uma vulnerabilidade social muito elevada. Em contrapartida, a freguesia de Marinha das Ondas apresenta uma vulnerabilidade baixa.

No município de Setúbal (fig. 9b) as oito freguesias apresentam uma vulnerabilidade social que varia entre muito baixa e elevada. As freguesias de Nossa Senhora da Anunciada e Sáo Sebastiāo apresentam vulnerabilidade elevada, contrariamente às freguesias de São Lourenço, São Simão, Santa Maria da Graça e Gâmbia, Pontes e Alto da Guerra, que apresentam uma vulnerabilidade muito baixa.

No município de Vila do Bispo (fig. 9c) as cinco freguesias apresentam uma vulnerabilidade social que varia entre muito baixa e muito elevada. A freguesia de Barão de Sáo Miguel das potencialmente afetadas, a que apresenta uma vulnerabilidade muito elevada, ao invés da freguesia da Raposeira que apresenta uma vulnerabilidade muito baixa.

\section{Avaliação da vulnerabilidade tributária}

No que respeita ao município da Figueira da Foz a VT varia entre muito baixa a muito elevada com diferenças marcadas ao longo do território municipal. Se analisarmos somente a área potencialmente inundada, os valores mais 

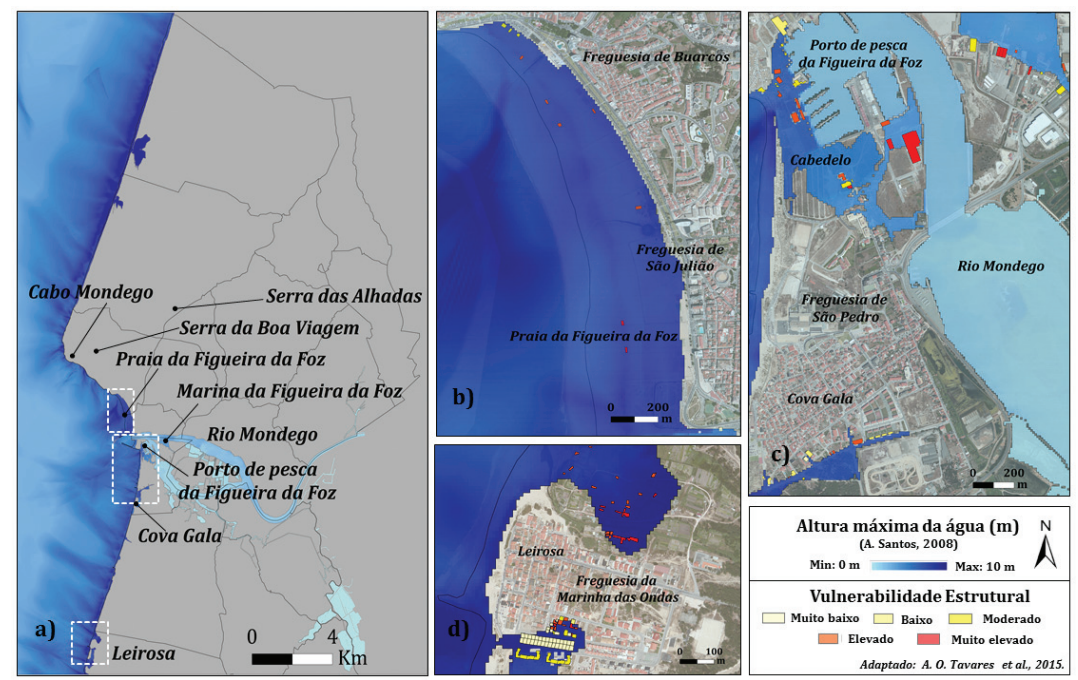

Fig. 6 - a) Avaliação da Vulnerabilidade Estrutural no município da Figueira da Foz; b) Detalhes nas freguesias de Buarcos e São Julião; c) Detalhes na freguesia de São Pedro (Cabedelo e Cova-Gala); d) Detalhes na freguesia da Marinha das Ondas (Leirosa).

Fig. 6 - a) Structural vulnerability assessment in Figueira da Foz municipality; b) Details in Buarcos and São Julião parishes; c) Details in São Pedro parish (Cabedelo and Cova Gala); d) Details in Marinha das Ondas parish (Leirosa).

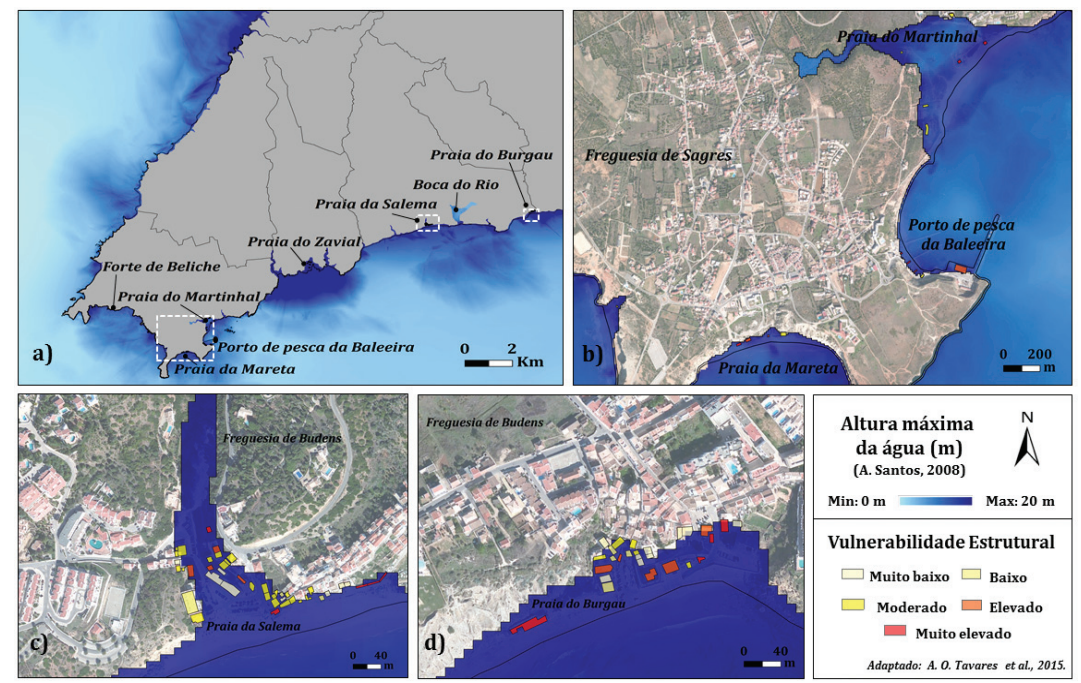

Fig. 7 - a) Avaliação da Vulnerabilidade Estrutural no município de Setúbal; b) Deta-

lhes no Outão; c) Detalhes na área urbana de Setúbal; d) Detalhes na Mitrena.

Fig. 7 - a) Structural vulnerability assessment in Setúbal municipality; b) Details in Outão; c) Details in urban area of Setúbal; d) Details in Mitrena. 
elevados são observados na zona de Buarcos e de São Juliáo (fig. 10a) devido ao facto de estarmos na presença de áreas urbanas consolidadas, onde os coeficientes são diferentes.

Por outro lado observa-se os valores mais baixos nas áreas rurais (predomínio da agricultura e floresta) e áreas naturais. $\mathrm{Na}$ área do Cabedelo e do porto (fig. 10a), os coeficientes de afetação apresentam o mesmo valor, apresentando cada um deles uma vulnerabilidade moderada.

No município de Setúbal a VT varia entre muito baixa a muito elevada. Verifica-se uma diferença entre as áreas urbanas, naturais (Salinas) e industriais (Mitrena). A área urbana de Setúbal (fig. 10b) apresenta uma vulnerabilidade tributária elevada, explicada pela presença do núcleo urbano consolidado e onde os diferentes coeficientes de afetação sofrem um agravamento.

No município de Vila do Bispo a VT varia igualmente entre muito baixa e muito elevada. Verifica-se uma clara distinção entre as áreas urbanas e as áreas naturais/rurais. Sagres, porto da Baleeira e ainda a faixa costeira do Martinhal são as zonas que apresentam os valores mais elevados de vulnerabilidade (fig. 10c). Por outro lado, os valores mais baixos coincidem com as áreas menos artificializadas e com claro predomínio natural/rural.

A área do Burgau (fig. 10c) apresenta uma vulnerabilidade tributária elevada, facto explicado por estarmos na presença de um núcleo balnear consolidado, com alguma pressão urbanística e onde os diferentes coeficientes de afetação sofrem um agravamento.

\section{Índice Compósito de Vulnerabilidade}

No que respeita aos resultados do ICV a Figueira da Foz (fig. 11), este apresenta uma média de 1,95 e um desvio padrão de 0,29. Observa-se claramente que os valores mais elevados surgem junto à costa, existindo uma diminuição da vulnerabilidade para o interior. Destaca-se o facto de o ICV ser influenciado pelas características morfológicas e estruturais da área de estudo, variando entre muito baixo e muito elevado. Verifica-se que 6\% da área 


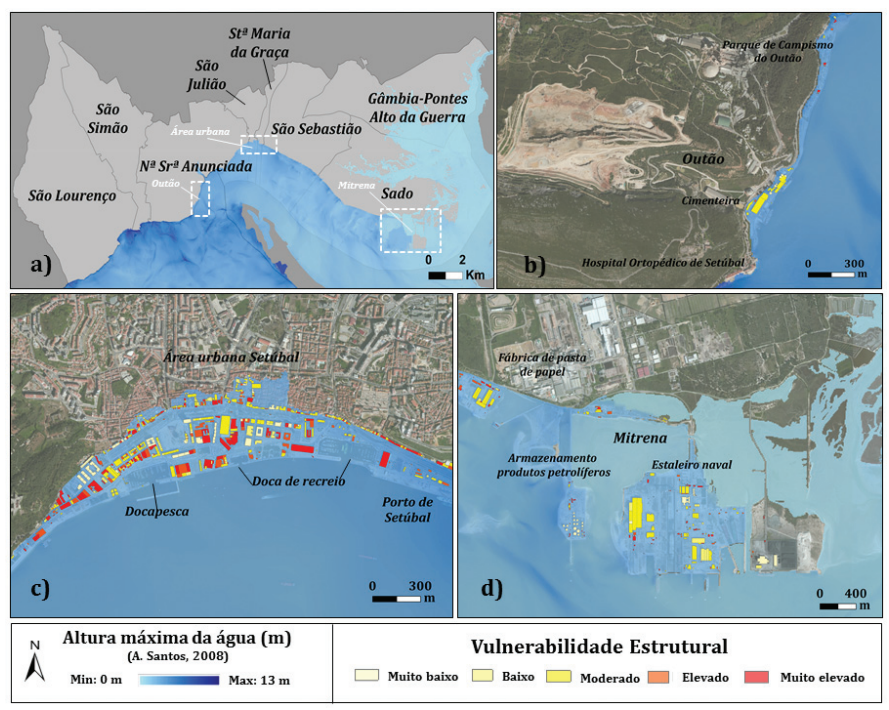

Fig. 8 - a) Avaliação da Vulnerabilidade Estrutural no município de Vila do Bispo; b) Detalhes na freguesia de Sagres; c) Detalhes na freguesia de Budens (Salema); d)

Detalhes na freguesia de Budens (Burgau).

Fig. 8 - a) Structural vulnerability assessment in Vila do Bispo municipality: b) Details in Sagres parish; c) Details in Budens parish (Salema); d) Details in Budens parish (Burgau).
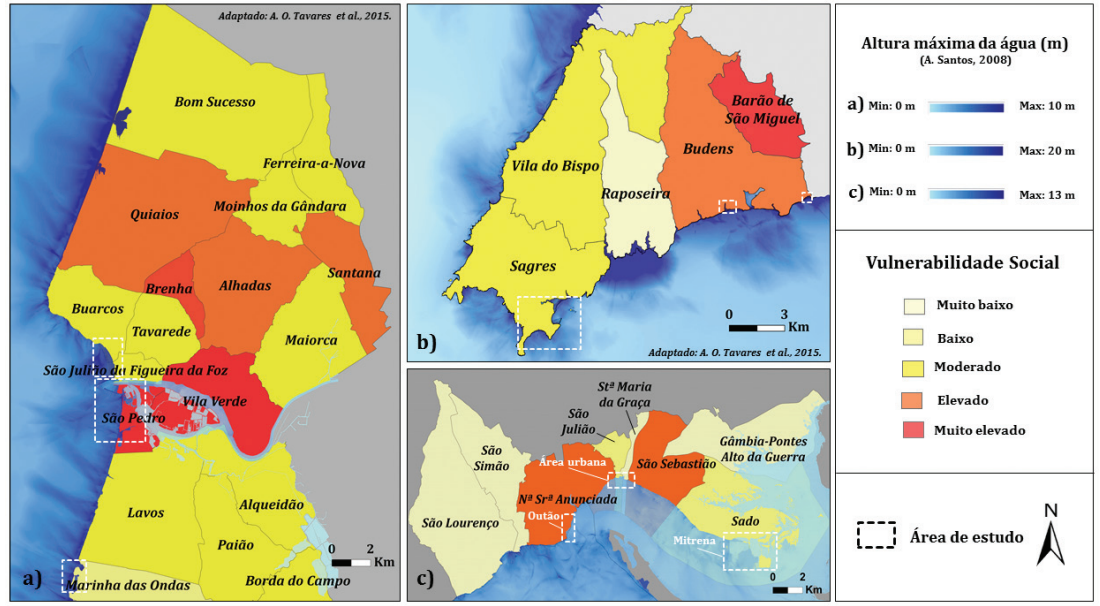

Fig. 9 - a) Avaliação da vulnerabilidade social no município da Figueira da Foz; b) Avaliação da vulnerabilidade social no município de Setúbal c) Avaliação da vulnerabilidade social no município de Vila do Bispo.

Fig. 9 - a) Social vulnerability assessment in Figueira da Foz municipality; b) Social vulnerability assessment in Setúbal municipality; c) Social vulnerability assessment in Vila do Bispo municipality. 
é classificada como muito elevado, correspondendo a edifícios e zona costeira, especialmente as freguesias de Buarcos, São Julião e São Pedro (fig. 11a; b; c). A vulnerabilidade elevada corresponde a pequenos troços litorais e às salinas, enquanto $43 \%$ da área apresenta uma vulnerabilidade moderada (zona costeira a norte de Quiaios e a sul da Cova Gala, zonas ribeirinhas do Mondego, porto de pesca da Figueira e marina) (fig. 11b). Com ICV baixo e muito baixo estão identificadas as zonas interiores da área de estudo, o estuário do Mondego e as áreas da Leirosa (fig. 11c).

Relativamente ao município de Setúbal (fig. 12) os resultados do ICV demonstram uma média de 2,33 e um desvio padráo de 0,34. Em termos gerais verifica-se que os maiores valores de ICV são registados na área urbana de Setúbal (fig. 12b), sobressaindo o estrutural em relaçáo aos outros índices.

Em termos percentuais, $97 \%$ da área apresenta um ICV muito baixo, 1,8\% baixo, 0,7\% moderado, 0,3\% muito elevado e por último, $0,2 \%$ da área apresenta um ICV elevado.

No que respeita ao município de Vila do Bispo (fig. 13) os resultados do ICV demonstram uma média de 1,76 e um desvio padrão de 0,33 . Em termos gerais verifica-se que os maiores valores de ICV são registados nas zonas costeiras de cota baixa (e.g., Boca do Rio) e nos principais núcleos balneares (Sagres, Salema, Burgau), com $9 \%$ da área de estudo a corresponder a vulnerabilidade muito elevada e $22 \%$ a níveis de vulnerabilidade alta. Cerca de $31 \%$ da área de estudo apresenta um ICV moderado, que coincide com troços costeiros de transiçáo entre a costa arenosa e a costa de arriba. Por último, os valores de vulnerabilidade baixa (23\%) e muito baixa (15\%) correspondem genericamente a áreas dominadas por arribas e a áreas interiores.

Neste município o ICV é fortemente influenciado pelas características morfológicas da área de estudo, com destaque para o parâmetro declive e uso e ocupação do solo, bem como pela componente tributária e social da vulnerabilidade. 

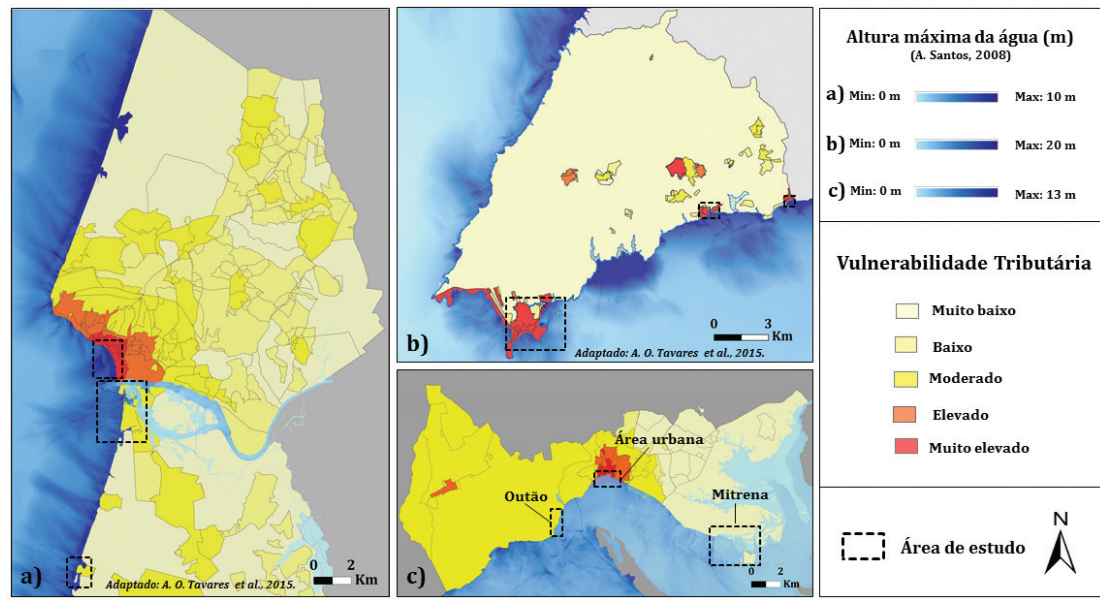

Fig. 10 - a) Vulnerabilidade tributária no município da Figueira da Foz; b) Vulnerabilidade tributária no município de Setúbal; c) Vulnerabilidade tributária no município de Vila do Bispo.

Fig. 10 - a) Taxable property vulnerability in Figueira da Foz municipality; b) Taxable property vulnerability in Setúbal municipality; c) Taxable property vulnerability in Vila do Bispo municipality.
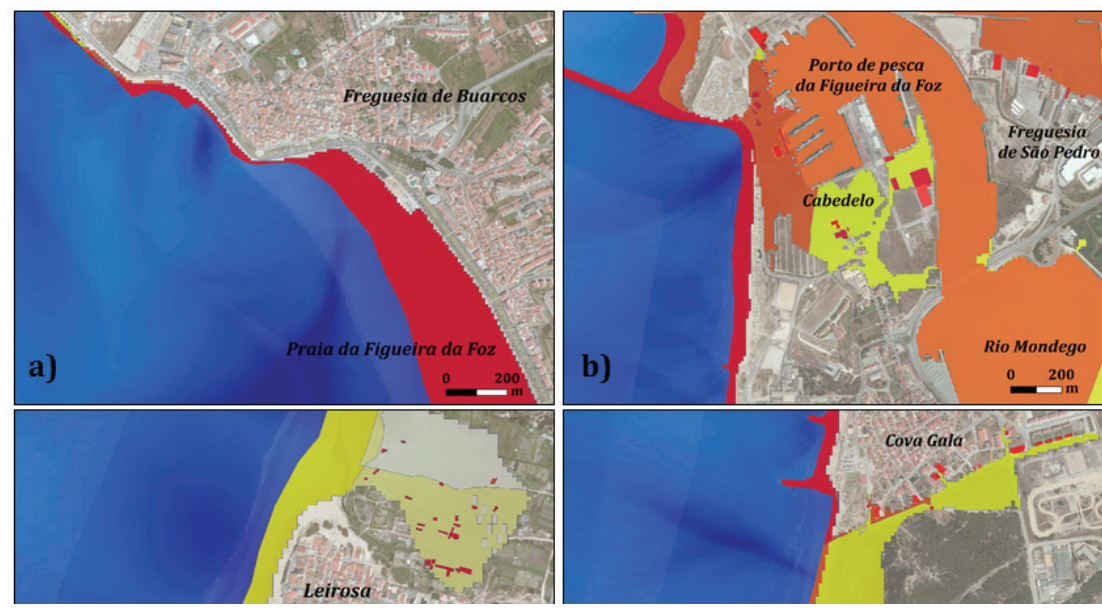

Fig. 11 - a) Detalhes do ICV (município da Figueira da Foz) nas freguesias de Buarcos e São Julião; b) e d) na freguesia de São Pedro (Cabedelo e Cova Gala); c) na freguesia de Marinha das Ondas (Leirosa).

Fig. 11 - a) CVI details (Figueira da Foz municipality) in Buarcos and Säo Julião parishes; b) and d) in São Pedro parish (Cabedelo and Cova Gala); c) in Marinha das Ondas parish (Leirosa). 

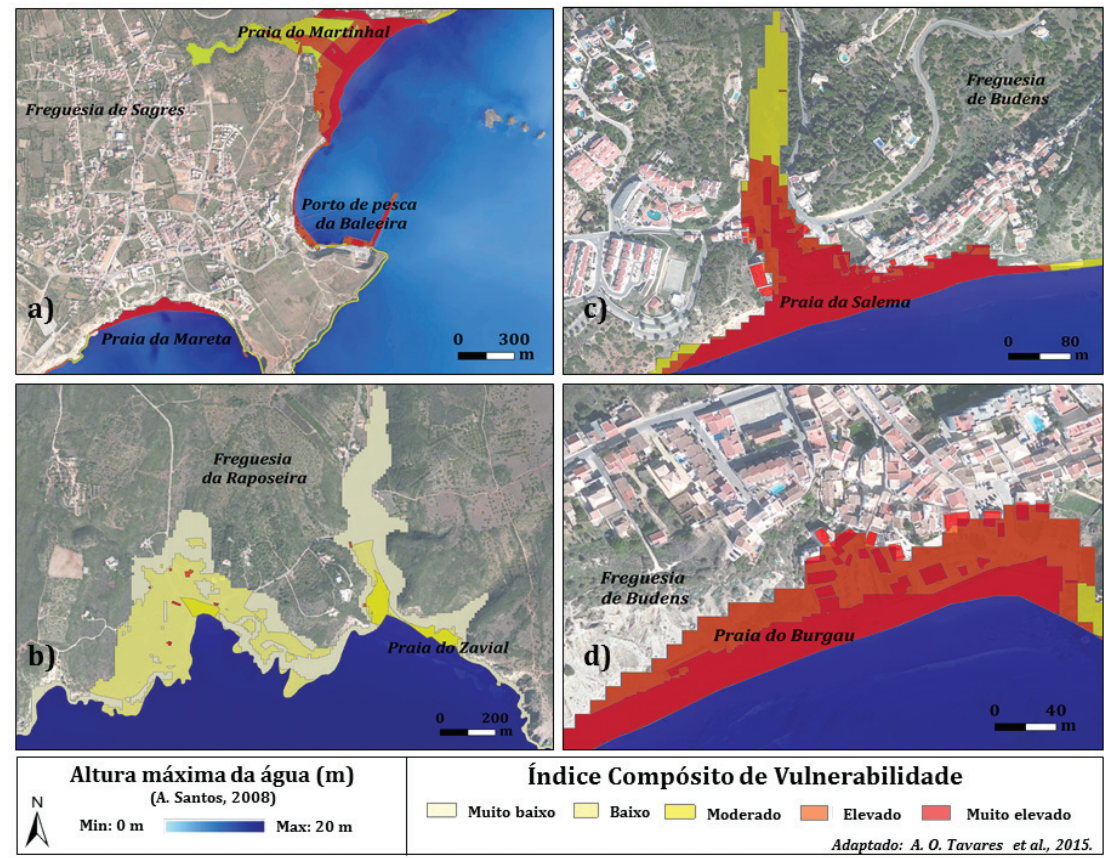

Fig. 12 - a) Detalhes do ICV (município de Setúbal) no Outáo; b) na área urbana de Setúbal; c) na Mitrena.

Fig. 12- a) CVI details (Setúbal municipality) in Outão; b) in urban area of Setúbal; c) in Mitrena.

\section{Conclusões}

A metodologia multidimensional apresentada no presente artigo, através da introdução de novos parâmetros que a diferenciam das suas precedentes, permitiu realizar uma avaliação abrangente da vulnerabilidade associada à inundação por tsunami. A análise e avaliação da VM, VE, VS e VT permitiu compreender o território nas suas múltiplas dimensôes, sendo esta análise complementada pelo cálculo do ICV, que através da combinação das componentes, permitiu espacializar as diferentes dinâmicas e demonstrar a variabilidade da vulnerabilidade compósita ao longo do território em análise.

O cálculo da vulnerabilidade associada às quatro componentes, bem como o cálculo do ICV expressam diferenças entre as três áreas de estudo. No município da Figueira da Foz é possível observar que a vulnerabilidade 

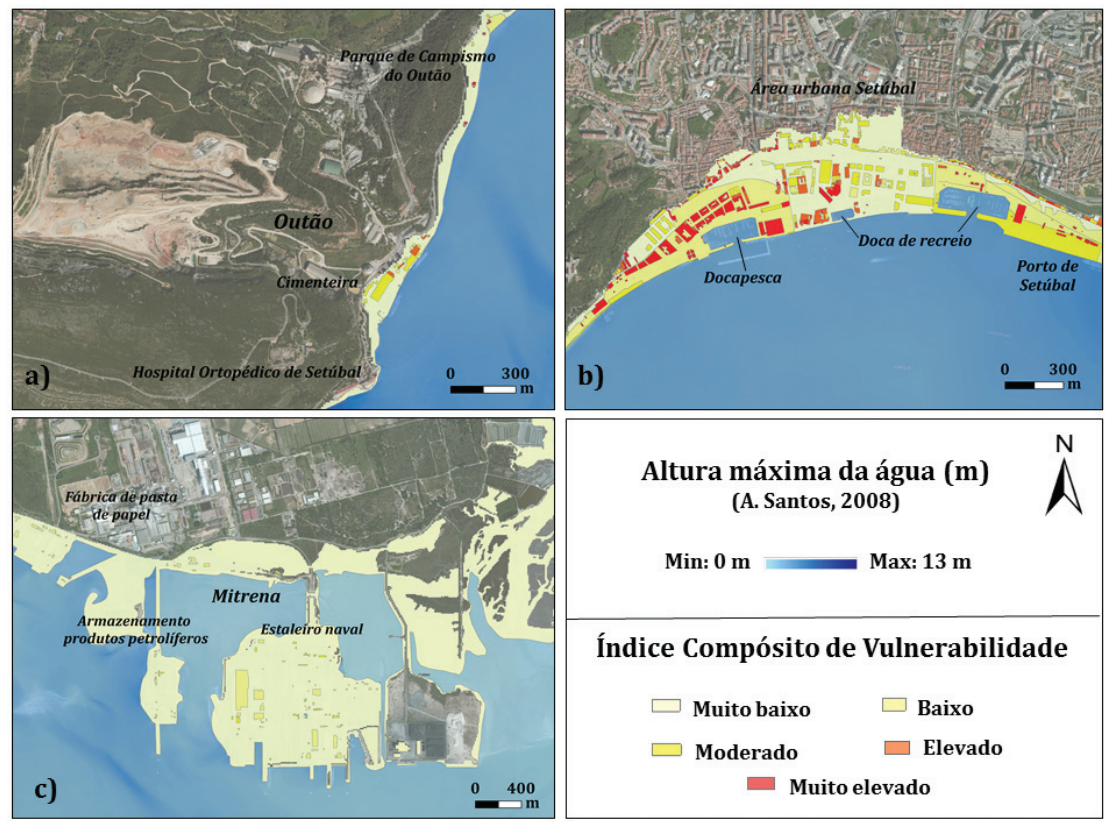

Fig. 13 - a) Detalhes do ICV (município de Vila do Bispo) na freguesia de Sagres; b) na freguesia de Raposeira (Zavial); c) na freguesia de Budens (Salema); d) na freguesia de Budens (Burgau).

Fig. 13 - a) CVI details (Vila do Bispo municipality) in Sagres parish; b) in Raposeira parish (Zavial); c) in Budens parish (Salema); d) in Budens parish (Burgau).

das diferentes componentes varia entre muito baixo a muito elevado, com exceção da VS que varia entre baixo a muito elevado. A análise permite também evidenciar que as características morfológicas e tributárias influenciam claramente a vulnerabilidade do território concelhio.

No que respeita ao município de Vila do Bispo, observa-se que as características morfológicas e tributárias marcam igualmente a vulnerabilidade do território, sendo que a dimensão social é mais marcante relativamente aos valores apresentados para o município da Figueira da Foz. Outra conclusão a retirar é o facto de nos municípios da Figueira da Foz e de Vila do Bispo a componente estrutural da vulnerabilidade apresentar valores mais baixos quando comparado com as restantes componentes, o que leva 
a concluir que a vulnerabilidade concelhia é fundamentalmente marcada pelas características intrínsecas ao território, sejam elas de natureza morfológica, social ou tributária e não tanto pelas características estruturais dos edifícios nele implantados, ao contrário de Setúbal, que apresenta uma vulnerabilidade marcadamente influenciada pelo estrutural em relaçáo aos outros índices. Esta conclusão suporta a construção da metodologia multidimensional utilizada no presente artigo, bem como demostra a importância das diferentes dimensôes da vulnerabilidade na temática da avaliação da vulnerabilidade face a tsunami.

O cálculo do Índice Compósito de Vulnerabilidade (ICV) permitiu identificar as áreas costeiras como aquelas que apresentam os maiores valores de vulnerabilidade, com exceção feita a alguns troços costeiros, nomeadamente na zona de Leirosa na Figueira da Foz e nas áreas dominadas pelas arribas no município de Vila do Bispo. Por outro lado verifica-se que a vulnerabilidade compósita (ICV) diminui em relação inversa ao aumento da distância à linha de costa, sendo que existem diferenças entre os dois municípios no que diz respeito às componentes que mais influenciam o cálculo do ICV.

A multiplicidade de fatores presentes no território e que contribuem de forma decisiva para a definição das diferentes vulnerabilidades com expressão no território justificam a adoção de uma metodologia compósita de avaliação da vulnerabilidade face a um tsunami. Os diversos outputs que resultaram da aplicação da metodologia adotada no presente estudo podem servir como ferramenta de trabalho para os diferentes stakeholders com o intuito de poderem discutir e implementar medidas de prevenção, mitigaçáo e reduçáo do risco associado a tsunami.

Por outro lado os resultados obtidos podem também auxiliar no processo de gestão de emergência através da identificação das áreas mais vulneráveis e dos edifícios potencialmente afetados. Podem ainda ser uma base para a definição de rotas de evacuaçáo e definição de edifícios para abrigo em caso de tsunami. Constitui ainda um suporte à definição de políticas de ordenamento do território que salvaguardem e integrem a temática dos riscos. 


\section{Agradecimento}

Este artigo foi suportado pelo Projeto TsuRiMa - Gestáo do risco de tsunamis para o ordenamento do território e a proteção civil, Projeto PTDC/ CS-GEO/118992/2010, Fundação para a Ciência e Tecnologia (FCT).

\section{Bibliografia}

Almeida, A. (1995). Dunas de Quiaios, Gândara e Serra da Boa Viagem. Uma abordagem ecológica da paisagem. Tese de Doutoramento, Universidade de Coimbra.

AT - Autoridade Tributária e Aduaneira. (2014). http://www.e-financas.gov.pt/SIGIMI/default.jsp.

Bana e Costa, C. A., Silva P. A. e Correia F. N. (2004). Multicriteria Evaluation of Flood Control Measures: The case of Ribeira do Livramento. Water Resources Management 18:263-283. http:// link.springer.com/article/10.1023\%2FB\%3AWARM.0000043163.19531.6a

Bana e Costa, C. A. e Chargas, M. (2004). An example of how to use MACBETH to build a quantitative value model based on qualitative value judgements. European Journal of Operational Research. 153:323-331. http://www.emeraldinsight.com/bibliographic_databases. htm?id=1313655\&show=abstract

Baptista, Maria Ana e Miranda, Jorge (2009). Revision of the Portuguese catalog of tsunamis. Nat. Hazards Earth Syst. Sci., 9, 25-42, doi:10.5194/nhess-9-25-2009. http://www.nat-hazardsearth-systsci.net/9/issue1.html

Barros, J. L., Emídio, A., Santos, A. e Tavares, A.O. (2015). Composite methodology for tsunami vulnerability assessment based on the numerical simulation of 1755 Lisbon tsunami-application on two Portuguese coastal areas. In Safety and Reliability: Methodology and Applications, ed Nowakowski et al. Taylor e Francis Group, 1581-1588. London.

Carta Social (2013). http://www.cartasocial.pt, Gabinete de Estratégia e Planeamento.

Chen, W., Susan, S., Emrich, C. e Shi, P. (2013). Measuring social vulnerability to natural hazards in the Yangtze river delta region, China. International Journal of Disaster Risk Science. 4:169-181.

Coelho, A. (1980). A Cartografia Geotécnica no Planeamento Regional e Urbano. Experiência de Aplicação na Região de Setúbal. Tese apresentada ao concurso para especialista do Laboratório Nacional de Engenharia Civil, Lisboa. pp.125-127.

Cunha, P. P., Pinto, P. e Dinis, J. L. (1997). Evolução da fisiografia e ocupação antrópica na área estuarina do Rio Mondego e regiấo envolvente (Portugal centro-oeste), desde 1947. Territorium 4:99-124.

Cutter, S., Boruff, B., e Shirley, W. (2003). Social vulnerability to environmental hazards. Social Science Quarterly, 84:242-261. http://onlinelibrary.wiley.com/doi/10.1111/15406237.8402002/abstract.

Dall'Osso, F., Gonella, M., Gabbianelli, G., Withycombe, G., e Dominey-Howes, D. (2009). A revised (PTVA) model for assessing the vulnerability of buildings to tsunami damage. Natural Hazards and Earth System Sciences, 9: 1557-1565. 
Dall'Osso, F., Maramai, A., Graziani, L., Brizuela, B., Cavalletti, A., Gonella, M. e Tinti S. (2010). Applying and validating the PTVA-3 model at the Aeolian Islands, Italy: assessment of the vulnerability of buildings to tsunamis. Natural Hazards and Earth System Sciences, 10:1547-1562.

Dawson, A. G., Hindson, R., Andrade, C., Freitas, C., Parish, R., e Bateman, M. (1995). Tsunami sedimentation associated with the Lisbon earthquake of 1 November AD 1755: Boca do Rio, Algarve, Portugal. The Holocene, 5: 209-215.

Dominey-Howes, D., e Papathoma, M. (2007). Validating a tsunami vulnerability assessment model (the PTVA model) using field data from the 2004 Indian Ocean tsunami. Natural Hazards, 40:113-136. http://link.springer.com/article/10.1007/s11069-006-0007-9\#.

Faria, C. (1981). Novo fenómeno urbano - aglomeração de Setúbal. Ensaio de sociologia urbana. Textos de ciências sociais, 18. Ediçáo assírio e alvim. Lisboa, L24605. 5 p.

ICNF. (2015). Instituto da Conservação da Natureza e das Florestas, IP - Portugal, Lisboa. http:// www.icnf.pt/portal/ap/r-nat/rnes/geo.

INE. (2011). Censos de Portugal de 2011, Instituto Nacional de Estatística, IP - Portugal, Lisboa. Disponível online no endereço url: http://www.ine.pt (acedido em 17 de Agosto de 2014).

INE. (2013). Instituto Nacional de Estatística, IP - Portugal, Lisboa. http://www.ine.pt.

Ismail, H., Abd Wahab, A., Mohd Amin, M., Mohd Yunus, M., Jaffar Sidek, F., e Esfandier, J. B. (2012). A 3-tier tsunami vulnerability assessment technique for the north-west coast of Peninsular Malaysia. Natural Hazards. 63: 549-573. http://link.springer.com/article/10.1007/ s11069-012-0166-9\#.

LNEG. (1994). Carta Geológica de Portugal, 1:50 000, f. $38 B$ e 39A. Laboratório Nacional de Energia e Geologia, Unidade de Investigação de Geologia e Cartografia Geológica.

Mendes, J. M. (2009). Social Vulnerability Indexes as Planning Tools: Beyond the preparedness paradigm. Journal of Risk Research 12:43-58. http://www.tandfonline.com/doi/citedby/10.10 80/13669870802447962\#tabModule.

Mendes, J. M., Tavares, A. O., Freiria, S. e Cunha, L. (2011). Vulnerabilidade social aos riscos naturais e tecnológicos em Portugal. Revista Critica de Ciências Sociais, 93:95-128.

Mendes, José e Freiria, Susana (2012). O risco de tsunami em Portugal: Perceçôes e Práticas. OSIRIS, Centro de Estudos Sociais da Universidade de Coimbra, 25p. http://www.ces.uc.pt/ osiris/pages/pt/publicacoes/relatorios.php.

Papathoma, M., Dominey-Howes, D., Zong, Y., e Smith, D. (2003). Assessing tsunami vulnerability, an example from Herakleio, Crete. Natural Hazards and Earth System Sciences, 3:377e389.

http://www.nat-hazards-earth-systsci.net/3/377/2003/nhess-3-377-2003.html.

Papathoma, M., e Dominey-Howes, D. (2003). Tsunami vulnerability assessment and its implications for coastal hazard analysis and disaster management planning, Gulf of Corinth, Greece. Natural Hazards and Earth System Sciences, 3:733-747. http://www.nat-hazards-earthsystsci. net/3/733/2003/nhess-3-733-2003.html.

Pendleton, E., Barras, J., Williams, S., and Twichell, D. (2010). Coastal vulnerability assessment of the Northern Gulf of Mexico to sea-level rise and coastal change. U.S Geological Survey Report 2010-1146. http://pubs.usgs.gov/of/2010/1146/pdf/ofr2010-1146.pdf.

PORDATA. (2013). Base de dados Portugal contemporâneo. http://www.pordata.pt.

Rocha, R., Ramalho, M., Manuppella, G. and Zbyszewski, G. (1979). Notícia explicativa da folha 51-B Vila do Bispo da Carta Geológica de Portugal à escala 1:50000. Direção Geral de Geologia e Minas - Serviços Geológicos de Portugal. Lisboa. 
Rocha, R., Manuppella, G., Mouterde, R., Ruget, C. e Zbyszewski, G. (1981). Notícia explicativa da folha 19-C Figueira da Foz da Carta Geológica de Portugal à escala 1:50000. Direção Geral de Geologia e Minas - Serviços Geológicos de Portugal. Lisboa.

Santos, Ângela (2008). Tsunami Hazard Assessment in Portugal by the Worst Case Scenario: The November 1st, 1755 Lisbon Tsunami, PhD Thesis, Tohoku University, 210 pp.

Santos, Ângela et al. (2009). "The 1755 Lisbon Tsunami: Tsunami source determination and its validation”. Jour. Dis. Res., 4:1, 41-52. http://www.fujipress.jp/finder/xslt.php?mode=presen t\&inputfile=DSSTR000400010006.xml.

Santos, Ângela et al. (2011). "O tsunami de 1755 e a avaliação da perigosidade em Portugal continental”. VIII Congresso da Geografia Portuguesa, Repensar a Geografia para Novos Desafios, Comunicaçóes, APG, Lisboa, 6 p., Outubro 26-29, https://sites.google.com/a/campus.ul.pt/ tsurima/publications.

Santos, A., Fonseca, N. Pereira, S., Zêzere, J.L., Koshimura, S. (2012). Tsunami risk assessment at Figueira da Foz, Portugal. Paper presented in 15 World Conference of Earthquake Engineering. September 24 - 28, in Lisbon, Portugal. http://riskam.ul.pt/images/pdf/paper_1931.pdf.

Santos, Ângela e Koshimura, Shunichi (2013). “Tsunami hazards at Setubal urban area considering the 1755 Lisbon Tsunami”. Pinto Correia, T.; Henriques, V.; Juliāo, R.P. (Eds.), IX Congresso da Geografia Portuguesa - Geografia: Espaço, Natureza, Sociedade e Ciência, p.930-935, Évora, Portugal, 28-30 Novembro,2013.ISBN:978-972-99436-6-9. https://sites.google.com/a/campus. ul.pt/tsurima/publications.

Santos, A. e Koshimura, S. (2015) The Historical Review of the 1755 Lisbon Tsunami, Journal of Geodesy and Geomatics Engineering, 1, 38-52 doi: 10.17265/2332-8223/2015.04.004 http:// www.davidpublisher.com/Public/uploads/Contribute/5538548886a24.pdf.

Schmidtlein, M., Deutsch, R., Piegorsch, W. e Cutter, S. (2008). A Sensitivity Analysis of the Social Vulnerability Index. Risk Analysis. 28:1099-1114.

http://onlinelibrary.wiley.com/doi/10.1111/j.1539-6924.2008.01072.x/full.

Tavares, Alexandre Oliveira et al. (2011). Perceçâo dos riscos naturais e tecnológicos, confiança institucional e preparação para situaçôes de emergência: O caso de Portugal continental. Revista Crítica de Ciências Sociais, 93. 167-193. http://rccs.revues.org/1380.

Tavares, A.O., Barros, J. L. e Santos, A. (2015). Tsunami vulnerability in two coastal areas of Portugal: a multidimensional approach. In Risk, Models and Applications, CODATA Berlin, Germany. 